\title{
A colaboração do enfermeiro no processo de amamentação por primíparas: superando barreiras e dificuldades
}

The collaboration of nus in the process of breastfeeding by primiparous: overcoming barriers and difficulties Colaboración del enfermedad en el proceso amoroso primario: superando barreras y dificultades

\begin{abstract}
RESUMO
Objetivo: analisar a atribuição do enfermeiro na assistência às primíparas com dificuldades em amamentar. Método: Consiste em revisão de literatura descritiva, com publicações de 2013 a 2020, pesquisadas nas bases de dados: Lilacs, SciELO, Medline e BDENF. Resumo: A mulher é quem decide amamentar ou não, entretanto, essa prática pode ser influenciada por diversos fatores ambientais e sociais, além de intercorrências como o ingurgitamento mamário, a mastite, a dificuldade do bebê em realizar a pega correta e as dúvidas sobre a produção de leite. Fatores que podem ocorrer com qualquer puérpera, porém, para as primíparas a dificuldade pode ser maior devido à inexperiência da mesma. Conclusão: 0 enfermeiro deve auxiliar as primíparas para garantir 0 êxito nesse processo e prevenir possiveis intercorrências. É evidente a importância de uma consulta de enfermagem detalhada, visando uma relação de confiança e promovendo o bem-estar da mãe, do filho e de seus familiares.
\end{abstract}

DESCRITORES: Aleitamento Materno; Cuidados de Enfermagem; Gestante.

\section{ABSTRACT}

Objective: to analyze the assignment of the nurse to assist primiparae with difficulties in breastfeeding. Method: It consists of a review of descriptive literature, with publications from 2013 to 2020, researched in the databases: Lilacs, SciELO, Medline and BDENF. Abstract: It is the woman who decides to breastfeed or not, however, this practice can be influenced by several environmental and social factors, in addition to intercurrences such as breast ingurgitation, mastitis, the baby's difficulty in performing the correct handle and doubts about milk production. Factors that can occur with any puerperal, however, for the primiparae the difficulty can be greater due to their inexperience. Conclusion: The nurse must help the primiparas to guarantee the success in this process and prevent possible intercurrences. It is evident the importance of a detailed nursing consultation, aiming at a relationship of trust and promoting the well-being of the mother, the son and his relatives.

DESCRIPTORS: Breastfeeding. Nursing care. Pregnant.

\section{RESUMEN}

Objetivo: analizar la asignación de la enfermera en la asistencia a las primíparas con dificultades para la lactancia. Método: Consiste en una revisión de la literatura descriptiva, con publicaciones de 2013 a 2020, buscadas en las bases de datos: Lilacs, SciELO, Medline y BDENF. Resumen: Es la mujer la que decide amamantar o no, sin embargo, esta práctica puede estar influenciada por varios factores ambientales y sociales, además de intercurrencias como la ingestión de leche, la mastitis, la dificultad del bebé para realizar el manejo correcto y las dudas sobre la producción de leche. Factores que pueden ocurrir con cualquier puerperal, sin embargo, para las primíparas la dificultad puede ser mayor debido a su inexperiencia. Conclusión: La enfermera debe ayudar a las primíparas para garantizar el éxito en este proceso y prevenir posibles intercurrencias. Es evidente la importancia de una consulta de enfermería detallada, con el fin de establecer una relación de confianza y promover el bienestar de la madre, el niño y sus familiares.

DESCRIPTORES: Lactancia materna. Cuidado de enfermería. Embarazada.

RECEBIDO EM: 17/08/2020 APROVADO EM: 31/08/2020

\section{Bárbara Peixoto Dantas}

Enfermeira - Graduada pelo Centro Universitário de Goiatuba - UNICERRADO. Pós graduanda em Urgência e Emergência. ORCID: 0000-0002-5519-9745 


\section{Kennia Rodrigues Tassara}

Enfermeira. Especialista em Urgência e Emergência. Docente no Centro Universitário de Goiatuba - UNICERRADO. ORCID: 0000-0001-5435-4320

\section{Pedro Henrique Ataides de Moraes}

Graduando em Medicina - UNICERRADO.

ORCID: 0000-0002-6636-5518

\section{Ricardo Ansaloni de Oliveira}

Educador Físico. Mestre pela Universidade Federal do Triangulo Mineiro - UFTM. Docente no Centro Universitário de Goiatuba - UNICERRADO.

ORCID: 0000-0002-2310-9047

\section{Lívia Vieira Simões Ansaloni}

Enfermeira. Especialista em Enfermagem do Trabalho e Obstetrícia. Docente orientadora pelo Centro Universitário de Goiatuba - UNICERRADO.

ORCID: 0000-0001-6780-6867

\section{INTRODUÇÃO}

A gestação compreende um período de transformações para as mulheres primíparas, principalmente em relação ao seu papel na sociedade, o que acarreta sentimentos ambíguos, devido ao desconhecido. $\mathrm{O}$ impacto é gerado quando a mulher reflete sobre seu futuro cheio de dúvidas, medo e incertezas, mas ao mesmo tempo a emoção toma conta em virtude da espera de uma criança, sendo sinônimo de alegria e satisfação. Esses sentimentos são vivenciados de acordo com as experiências, os valores, a relação familiar e a situação socioeconômica de cada uma, o que pode de alguma maneira intervir na relação entre mãe e filho e até mesmo no processo de amamentação ${ }^{(1)}$.

A atenção voltada para a Mulher e o Recém-Nascido (RN) é prática fundamental para o sucesso da amamentação. Por esse motivo, diversas ações e políticas vem sendo desenvolvidas desde a década de 1980, com o intuito de incentivar o Aleitamento Materno (AM). Entretanto, para alcançar esse feito é imprescindível que os profissionais das Unidades Básicas de Saúde (UBS) estejam em concordância com as unidades hospitalares, introduzindo temas relacionados à amamentação ainda durante o pré-natal, proporcionando um ambiente agradável e acolhedor, para que essas mulheres ex- ponham suas dúvidas e sintam-se seguras e preparadas para este momento ${ }^{(2)}$.

O Aleitamento Materno Exclusivo é ideal para crianças desde o nascimento até os seis meses, posteriormente, o leite materno deve ser ofertado de modo complementar até os dois anos de idade ou mais, pois a composição desse alimento é capaz de suprir as necessidades do organismo, ou seja, é espécie-específico, o que viabiliza o crescimento e desenvolvimento saudável dos lactentes. Além dos inúmeros benefícios que essa prática proporciona à mãe, ao bebê e a toda família, sendo a mais eficientes formas de alimentação da humanidade ${ }^{(3,4)}$.

Existem inúmeras constatações científicas que comprovam a supremacia do leite materno sobre os demais, principalmente como fonte de nutrição, de defesa contra enfermidades pela transmissão de anticorpos e de ternura. Todavia, os órgãos nacionais e internacionais encontram ainda dificuldades para difundir esses conhecimentos no meio social, sendo esta, uma realidade muito distante na maioria dos lares brasileiros. Neste aspecto os profissionais de saúde são indispensáveis para a reversão deste quadro, que não será alcançado apenas mediante o preparo teórico-científico, mas sim em decorrência de uma visão holística e humanística, capaz de entender os fatores emocionais, culturais e sociais que estão por trás da lactação, auxiliando a mulher na busca pelo processo de construção da maternidade, encorajando-a ainda a assumir o protagonismo desta fase ${ }^{(5)}$.

O enfermeiro é um dos principais profissionais envolvidos no processo educativo da mulher nutriz. Deve estar apto a identificar, assim como otimizar os momentos educativos, seja na área básica, ambulatorial ou hospitalar, garantindo que a mulher receba informações claras, contínuas e atualizadas, por meio de uma assistência qualificada e humanizada, de modo a facilitar a amamentação através da preparação e conscientização $\mathrm{da}$ gestante quanto à pratica da lactação ${ }^{(6)}$. Logo, o objetivo deste estudo foi analisar a atribuição do enfermeiro na assistência as primíparas com dificuldades no aleitamento materno.

\section{MÉTODOS}

Trata-se de uma revisão de literatura de caráter descritivo, que teve como propósito pesquisar, agrupar e examinar produções científicas que abrangiam o assunto proposto, publicadas no período de 2013 a 2020. O levantamento dos dados foi realizado nos meses de fevereiro a junho de 2020. Os descritores utilizados foram pesquisados no Descritores em Ciência da Saúde (DeCS) de acordo com o tema de obstetrícia: Aleitamento Materno, Cuidados de Enfermagem, Educação em Saúde, Saúde Materno-Infantil e 
Relações Mãe-Filho. Foram rastreadas publicações em português e inglês e, além dos DeCS foi utilizada a expressão: dificuldades de primíparas durante a amamentação, que auxiliou e norteou durante as buscas.

As bases de dados acessadas foram: SciELO e Lilacs, BDENF e MEDLINE indexadas na Biblioteca Virtual em Saúde (BVS). Os critérios de inclusão nas buscas de bases supracitadas foram publicações que abordavam sobre: primíparas em dificuldades de amamentar. Já os critérios de exclusão, foram publicações que não se encaixavam na faixa temporal delimitada.

\section{RESULTADOS}

A partir das bases de dados desse estudo foram localizados um total de 108 publicações potenciais, e destas 61 foram excluídos por duplicatas. Foi realizada análise mais detalhada dos 47 restantes, por meio de leitura de títulos e resumos, dos quais foram excluídos 26 com justificativas por não atenderem aos critérios de elegibilidade, permanecendo ao final um total de 21 publicações que atenderam aos critérios pré-estabelecidos e compuseram esta revisão (Figura 01).

\section{Figura 1- Fluxograma de informações das fases da revisão. Autora, 2020.}

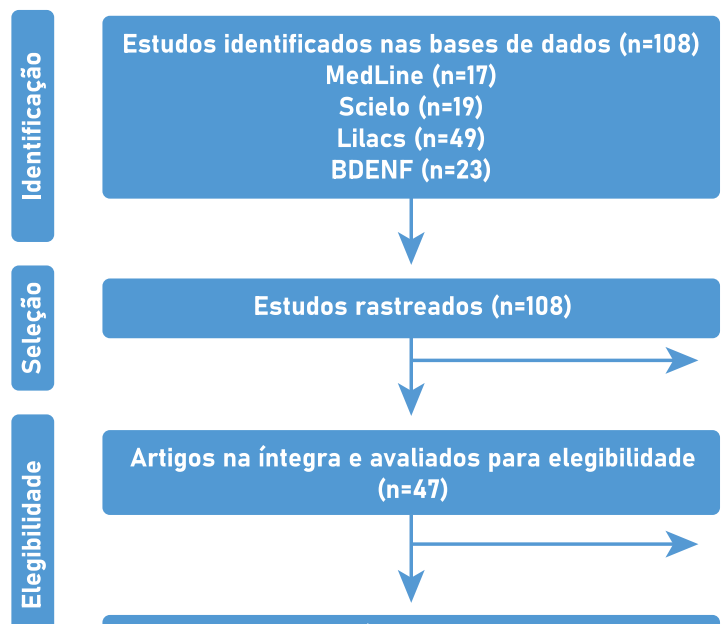

Estudos incluidos na revisão ( $n=21)$
Relatos excluidos ( $n=61)$

\section{DISCUSSÃO}

A mulher vê a amamentação como algo recíproco, uma vez que o ato de amamentar e a própria posição física da mulher e da criança já favorece ao abraço, ao estar junto, aconchegados, o que chega a assemelhar, praticamente, a um ato de dar e receber amor ${ }^{(7)}$.

A atitude da mulher referente à amamentação está associada à noção de si mesma na qualidade de mãe, que passa a ser protagonista de sua história, podendo imaginar-se de forma semelhante àquela que os outros já enxergam ou imaginam. São papéis que podem ser demonstrados por expressões verbais e não verbais, ou seja, por palavras, gestos, olhares, modo de falar, de tocar, de fazer carinho, pelo choro e pela expressão corporal, ao posicionar-se de pé ou sentada ${ }^{(8)}$.

$\mathrm{O}$ posicionamento das nutrizes sobre o processo de aleitar é dependente da percepção e conhecimento das mesmas, o que interfere de maneira direta nessa prática. A maioria das mulheres possuem apenas as instruções que são repassadas por médicos, em que a principal ação do AM é a prevenção de enfermidades, além dessas, algumas também sabem sobre a proteção imunológica, o valor nutricional, o favorecimento à

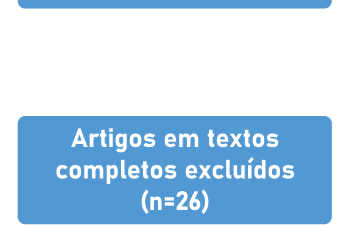

formação da arcada dentária do bebê e a relevância para saúde materna ${ }^{(9)}$.

É possível afirmar que os benefícios do AM são pouco compreendidos na sociedade. Existe um déficit de comunicação e repasse de informações para as mães, por isso as mesmas não valorizam a amamentação como deveria. Alguns benefícios dessa prática que quase não são abordados é em relação ao fortalecimento do vínculo mãe-filho, à diminuição de gastos da família com a alimentação da criança e a redução do risco de hemorragias nas puérperas ${ }^{(5)}$.

Existem inúmeras constatações científicas que comprovam a supremacia do leite materno sobre os demais, principalmente como fonte de nutrição, de defesa contra enfermidades pela transmissão de anticorpos e de ternura. Os benefícios para o RN incluem prevenção da mortalidade infantil; redução dos riscos de alergias, hipertensão, colesterol alto e diabetes mellitus; diminuição das chances de obesidade; contribuição para o bom desenvolvimento cognitivo e formação da cavidade bucal. Já para a mulher as vantagens abrangem prevenção de câncer de mama, ovário e útero, além de ser considerado um eficiente método anticoncepcional. Já para a família e a sociedade o incentivo é financeiro, pois as fórmulas lácteas infantis são onerosas ${ }^{(10)}$.

A primeira gestação fomenta sentimentos divergentes, causando medos e anseios pela falta de experiência, tudo isso contribui para o sucesso e/ou fracasso do desafio que é o AME. A maternidade para as primíparas é uma tarefa árdua, sem uma receita pronta, que exige maturidade e equilíbrio para lidar com o novo e inesperado "ser" mãe, surgindo questionamentos sobre a capacidade de educar um filho, a insegurança, a falta de preparo e aflição com o ato de amamentar. Desse modo, a rede de apoio às primíparas deve ser iniciada nas primeiras consultas pré-natais com profissionais preparados e aptos a estimular o AME, pois estas serão as referências dessas mulheres, o que irá despertar o desejo pelo ato ${ }^{(11)}$. 
A amamentação é enaltecida pelos profissionais de saúde devido aos seus aspectos biopsicossociais considerada como um ato natural. Desse modo, é imprescindível que o enfermeiro identifique junto a nutriz, todas suas dificuldades, tradições e convicções, afim de assimilar todo o processo de lactação vivenciado pela mesma, e como resultado será capaz de reconhecer as barreiras que impedem o AM, exercendo seu papel de maneira efetiva ${ }^{(12)}$.

Existe uma carência na abordagem dos profissionais com as gestantes em relação ao AME. Na maioria dos casos, $o$ incentivo e o apoio do enfermeiro à amamentação é insuficiente, e tal circunstância faz com que o profissional, constantemente, evidencie a utilização de intervenções inoportunas e desatualizadas, ou seja, a ausência da educação continuada dos enfermeiros. E também, a maioria dos profissionais de saúde são falhos ao prestar assistência durante o ciclo gravídico-puerperal, pois tratam o processo de forma segregada, quando na verdade deveria ser um cuidado holístico. Nesse período, é bastante incomum que a mulher receba atendimento de um mesmo estabelecimento, porém, de modo geral, existem lacunas que interferem no sistema de referência e contra referência, o que inviabiliza atenção qualificada ${ }^{(13,14)}$.

A mulher é a única responsável pela decisão de amamentar, entretanto essa prática pode ser alterada ou influenciada por diversos fatores ambientais. Entre eles, destacam-se o manejo hospitalar, os transtornos médicos antes e durante a gestação, as complicações durante e após o parto, o suporte e incentivo ao AM e o amparo da família ${ }^{(15)}$.

Um dos principais mitos que permeiam a sociedade sobre o leite materno é a questão do "leite fraco", essa visão equivocada é repassada por gerações familiares e até mesmo por profissionais da área de saúde, que na maioria das vezes relacionam o choro da criança com a fome, quando geralmente pode ser por inúmeros outros motivos. O leite da mãe é suficiente para sustentar o bebê, por isso essa devem ser bem orientada pelos profissionais de saúde sobre a produção e os valores nutricionais do leite materno, além disso devem ser trabalhadas a definição e diferenciação do colostro e do leite materno ${ }^{(16)}$.

Existe ainda a crença da produção insuficiente de leite, a mãe relaciona esse fato por não sentir as mamas cheias, ou nos primeiros dias de puerpério quando a produção é limitada. Por falta de orientação essa mulher experimenta os sentimentos de medo e receio com o crescimento e desenvolvimento e ganho de peso da criança. Diante do desespero e incertezas sobre seu volume de leite, a mesma opta por medidas drásticas e acaba introduzindo outro alimento sem a avaliação e instrução de um profissional, o que acaba interferindo e comprometendo o AME e seus benefícios ${ }^{(9)}$.

Durante o curso fisiológico da amamentação podem surgir barreiras e dificuldades que interferem nesse processo. Algumas dessas intercorrências podem ser prevenidas pelo enfermeiro, tais como: bebês com sucção insuficiente ou fraca, pega incorreta, ingurgitamento mamário, algia nos mamilos, fissuras mamilares, candidíase mamária, bloqueio de ductos lactíferos, mastite e abcessos mamários. Para que seja possível a prevenção, o enfermeiro deve ser capacitado quanto ao processo de lactação e suas complicações, para que seja capaz de intervir em qualquer situação ${ }^{(17)}$.

Os programas de promoção ao AME possuem três grandes obstáculos para serem superados no século XXI: o primeiro é como manter a amamentação desde o nascimento até o sexto mês. $\mathrm{O}$ segundo é como intervir na introdução da alimentação complementar ideal sem suspender a amamentação após o sexto mês de vida, e por último, mas não menos importante, como possibilitar uma alimentação adequada para as crianças de todos os grupos da população sem ocasionar desajustes na experiência de amamentação da população em geral ${ }^{(18)}$.
O enfermeiro deve abandonar o método mecanicista de trabalho e adotar medidas que contribuam para uma relação de confiança entre profissional e paciente, realizando visitas domiciliares para conhecer a singularidade de cada paciente e a interação familiar. A partir dessa vivência o profissional está apto para intervir nos problemas relacionados à saúde da comunidade. Assim, vale ressaltar a atenção primária como elo de fortalecimento para o AME, por meio de ações de educação em saúde durante o período gestacional até o puerperal ${ }^{(19)}$.

A função do enfermeiro é nortear a mulher primípara sobre o processo de amamentar e estabelecer um esquema de alimentação adequado ao lactente, pois o mesmo é detentor de conhecimento técnico-cientifico e possui formação crítica-reflexiva, sendo capaz de intervir nos problemas que possam surgir durante esse processo. O planejamento de suas ações deve ser voltada para educação em saúde, baseado no valor nutricional do leite materno, na prevenção de infecções e diminuição dos índices de mortalidade, no repasse de anticorpos maternos para o $\mathrm{RN}$, no vínculo emocional e os benefícios fisiológicos para ambos ${ }^{(9)}$.

A arte de amamentar deve ser um processo de aprendizado mútuo entre os profissionais de saúde, a família e a comunidade como um todo. Vale salientar que a família é a primeira rede de apoio que influencia na amamentação, entretanto o enfermeiro deve criar um vínculo de confiabilidade desde as primeiras consultas pré-natal, afim de conseguir repassar conhecimento e inspirar a primípara a relatar suas dúvidas, medos e anseios, para que possa intervir de forma favorável e contribuir de maneira positiva para o $\mathrm{AME}^{(12)}$.

O puerpério imediato é um momento crucial para o bom resultado da prática de amamentar, marcado pelo enfrentamento dos obstáculos com a amamentação ${ }^{(6)}$. E durante o puerpério o enfermeiro deve reforçar todas as orientações sobre o AM que foram 
repassadas durante o pré-natal, com intuito de reduzir os obstáculos durante a amamentação. Esse profissional deve auxiliar a lactante a colocar o bebê em uma posição confortável para ambos e a realizar uma pega correta; ressaltar a importância do início precoce do AM; frisar os malefícios do uso de chupetas e mamadeiras e nortear sobre a livre demanda do aleitamento ${ }^{(17)}$.

Logo após o nascimento o RN deve ser colocado imediatamente sob o peito da mãe de forma a propiciar o contato pele a pele e estabelecer o vínculo mãe-filho por meio do AM, essa medida não deve ser feita apenas em casos com contraindicação médica. É imprescindível que o bebê permaneça no contato pele a pele para se revigorar do parto e livremente encontrar o mamilo de forma instintiva, a fim de realizar a primeira mamada que pode ter duração de $45 \mathrm{mi}$ nutos ou mais, durante esse ato o bebê não deve ser perturbado e o fim da mamada deve ser espontânea ${ }^{(20)}$.

No AME em livre demanda o sinal de efetividade da ação é quando o lactente se afasta do seio materno sem que esse ato cause dor à lactante. O profissional de enfermagem deve alertar as nutrizes para situações como mamadas muito longas ou muito curtas, agitação e demonstração de insatisfação quando termina a mamada, pois pode significar problemas relacionados ao manejo e a técnica de amamentação, devendo ser corrigido logo que for percebido ${ }^{(21)}$.

A ordenha manual ou elétrica é um recurso utilizado garantir a continuidade na amamentação em situações de neces-

\section{O enfermeiro é} responsável por

oferecer assistência

durante todo o

período gravídico-

puerperal, sendo

o profissional

com maior

habilidade para

incentivar e

intervir no $\mathrm{AME}$,

principalmente

em mulheres

primíparas. sidades, Os profissional de enfermagem devem repassar orientações para que essa técnica não seja executada de forma exaustiva ou sob pressão, uma queixa recorrente é sobre a livre demanda, que se torna complicada nessa adaptação ${ }^{(5)}$.

No início da amamentação é comum que haja intercorrências, sendo verificada maior prevalência de traumas mamilares e ingurgitamento mamário. $\mathrm{O}$ enfermeiro deve detectar sua etiologia e traçar medidas para sua resolução, como passar o leite materno na região mamilo-areolar antes e depois das mamadas; realizar banho de sol nos seios por 15 minutos, de manhã entre 8-10 horas ou após as 16 horas; deixar a aréola flexível para começar a amamentação, preferencialmente pelo mamilo menos machucado e/ou dolorido; e para terminar a mamada, a sucção deve ser suspensa primeiro. E em casos de ingurgitamento e mastite buscar atenção ampla de cuidado ${ }^{(10)}$.

\section{CONCLUSÕES}

O enfermeiro é responsável por oferecer assistência durante todo o período gravídico-puerperal, sendo o profissional com maior habilidade para incentivar e intervir no AME, principalmente em mulheres primíparas. Por meio do planejamento de recursos e estratégias para adaptação a esta nova etapa que devem ser preparadas e frisadas desde o pré-natal. Assim a enfermagem possui o papel de educadores em saúde, com interação, atenção e diálogo com as puérperas, esclarecendo dúvidas e dificuldades.

\section{REFERÊNCIAS}

1. Alexandre SM, KUHN J. Cáp. 128: Assistência ao Puerpério e ao Aleitamento. In: Borges, D. R. et al. Atualização terapêutica de Prado, Ramos e Valle: diagnóstico e tratamento. $25^{\mathrm{a}}$ ed. Reformulada e atualizada. - São Paulo: Artes Médicas, 2014. 608611.

2Almeida JMD, Luz SDAB, Ued, F. D. V. Apoio ao aleitamento materno pelos profissionais de saúde: revisão integrativa da literatura. Revista Paulista de Pediatria. [In- ternet]. 2015. [acesso em 10 de agosto de 2020]. 33(3): 355-362. Disponivel em: https://www.scielo.br/scielo.php?pid=S0103-05822015000300355\&script=sci_arttext

3. Alves ALN, Oliveira MIC, Moraes JR. Iniciativa Unidade Básica Amiga da Amamentação e sua relação com o aleitamento materno exclusivo. Revista Saúde Pública, Rio de Janeiro (RJ). [Internet]. 2013. [acesso em 10 de agosto de 2020]. 47 (6), 1130-1140. Disponivel em: https://www.scielo.br/scielo.php?pi- 


\section{REFERÊNCIAS}

\section{$\mathrm{d}=$ S010305822015000300355\&script=sci_arttext}

4. Amaral LJX, Sales SS, Carvalho DPSRP, Cruz GKP, Azevedo IC, Júnior MAF. Fatores que influenciam na interrupção do aleitamento materno exclusivo em nutrizes. Revista Gaúcha de Enfermagem. [Internet]. 2015. [acesso em 10 de agosto de 2020]. 36, 127-134. Disponivel em: https://www.scielo.br/scielo.php?pi$\mathrm{d}=\mathrm{S} 198314472015000500127 \&$ script=sci_arttext\&tlng=pt

5 Andrade FR, Costa MS, Delfino S. Desafios do aleitamento materno em primíparas: a importância da assistência de enfermagem. Simpósio de TCC e Seminário de IC. [Internet]. 2016. [acesso em 10 de agosto de 2020]. 1;974-983, Disponível em: http://nippromove.hospedagemdesites.ws/anais_simposio/arquivos_up/documentos/artigos/0ae64744b522349c55f02da50bb79̄d19.pdf

6. Andrade RD, Santos MAC, Mello DF. Fatores relacionados à saúde da mulher no puerpério e repercussões na saúde da criança. Escola Anna Nery Revista de Enfermagem. [Internet]. jan./mar. 2015. [acesso em 10 de agosto de 2020]. 19 (1): 181-186. Disponivel em: https://www.scielo.br/scielo.php?pi$\mathrm{d}=\mathrm{S} 1414-81452015000100181 \&$ script=sci_arttext\&tIng=pt

7. Batista KRA, Farias MCAD, Melo WSN. Influência da assistência de enfermagem na prática da amamentação no puerpério imediato. Saúde em Debate, Rio de Janeiro (RJ). [Internet]. jan./ mar. 2013. [acesso em 10 de agosto de 2020]. 37 (96):130138. Disponivel em: https://www.scielo.br/scielo.php?pi$d=$ S010311042013000100015\&script=sci_arttext

8. Bouchet-Horwitz J. Ensuring Breastfeeding Success. ICAN: Infant, Child, \& Adolescent Nutrition. [Internet]. 2015. [acesso em 10 de agosto de 2020]. 7 (4): 208-211. Disponivel em: http:// journals.sagepub.com/doi/pdf/10.1177/1941406415595077

9. Brasil. Ministério da Saúde. Secretaria de Atenção à Saúde. Departamento de Atenção Básica. Dez passos para uma alimentação saudável: guia alimentar para crianças menores de dois anos: um guia para o profissional da saúde na atenção básica. - $2^{\mathrm{a}}$ ed. $-2^{\mathrm{a}}$ reimpressão - Brasília: Ministério da Saúde. [Internet]. 2013. [acesso em 10 de agosto de 2020]. Disponivel em: http://www.redeblh.fiocruz.br/media/10palims a_guia13.pdf

10. Carvalho ACO, Saraiva ARB, Gonçalves GAA, Soares JR, Pinto SL. Aleitamento Materno: Promovendo o Cuidar no Alojamento Conjunto. Revista Rene. [Internet]. 2013. [acesso em 10 de agosto de 2020]. 14(2): 241-251. Disponivel em: http://www. redalyc.org/pdf/3240/324027986003.pdf

11. Corrêa MSM, Oliveira KVF, Pedrosa EN, Ariani IS. Acolhimento no cuidado à saúde da mulher no puerpério. Cadernos de Saúde Pública. [Internet]. 2017. [acesso em 10 de agosto de 2020]. 33(3):12. Disponível em: 11Corrêa MSM, Oliveira KVF, Pedrosa EN, Ariani IS. Acolhimento no cuidado à saúde da mulher no puerpério. Cadernos

12. Lopes KDCL, Oliveira Neto JGD, Sá GGDM, Carvalho DAD, Monteiro MM, Martins MDCDC. Dificuldades nos cuidados ao recém-nascido: Realidades de puérperas primíparas. Revista de Saúde Pública de Santa Catarina. Florianópolis. [Internet]. 2015. [acesso em 10 de agosto de 2020]. 8(3): 19-33. Dispo- nível em: http://revista.saude.sc.gov.br/index.php/inicio/article/ view/351/317

13. Marinho MS, Andrade EM, Abrão ACFV. A atuação do(a) enfermeiro(a) na promoção, incentivo e apoio ao aleitamento materno. Revista Enfermagem Contemporânea, São Paulo (SP). [Internet]. 2015. [acesso em 10 de agosto de 2020]. 4(2): 189198. Disponível em: <https://www5.bahiana.edu.br/index.php/ enfermagem/article/view/598/547>. Acesso em: 07 de março de 2018.

14. Martins GBS, Vargas ED, Vaz CHGJ, Guilherme JM, Oliveira JF. A Importância do Aleitamento Materno Exclusivo até o $6^{\circ}$ Mês de Vida: A Percepção de Puérperas. Revista Científica da Saúde. [Internet]. 2020. . [acesso em 10 de agosto de 2020]. Bagé-RS, 2 (1). Disponivel em: http://ediurcamp.urcamp.edu.br/index.php/ revistasaude/article/view/3120/2423

15. Passanha A, Benício MHD, Venâncio SI, Reis MCG. Implantação da Rede Amamenta Brasil e prevalência de aleitamento materno exclusivo. Revista de Saúde Pública. [Internet]. 2013. [acesso em 10 de agosto de 2020]. 47(6): 1141-1148. Disponivel em: http://observatorio.fm.usp.br/bitstream/handle/ OPI/6145/art_PASSANHA_Implantacao_da_Rede_Amamenta_Brasil_e_prevalencia_de_por_2013.PDF? sequence=1\&is

16. PIO DAM, Capel MS. Os significados do cuidado na gestação. Revista Psicologia e Saúde. [Internet]. 2015. [acesso em 10 de agosto de 2020]. 7(1): 74-81. Disponivel em: https://pssa.ucdb. br/pssa/article/view/406

17. Roocci E, Fernandes RAQ. Dificuldades no aleitamento materno e influência no desmame precoce. Revista Brasileira de Enfermagem. [Internet]. 2014. [acesso em 10 de agosto de 2020]. 67(1): 22-27. Disponivel em: http://www.scielo.br/pdf/reben/ v67n1/0034-7167-reben-67-01-0022.pdf

18. Simões IAR, Rannó G, Salomon ASC, Martins MCM, Sá RAD. Influência dos Mitos e das Crenças nas Nutrizes Quanto Amamentação em uma Cidade do Vale do Paraíba. Revista Ciências em Saúde. [Internet]. 5 (3). 2015. [acesso em 10 de agosto de 2020]. 5 (3). Disponivel em: http://186.225.220.186:7474/ojs/ index.php/rcsfmit_zero/article/view/385

19. Sousa ASB. Dificuldades no aleitamento materno. [Tese]. (Mestrado em Enfermagem de Saúde Materna, Obstetrícia e Ginecologia) - Instituto Politécnico de Viseu, Escola Superior de Saúde de Viseu. [acesso em 10 de agosto de 2020]. Disponível em: <http://repositorio.ipv.pt/bitstream/10400.19/3347/1/ AnaSofiaBarradas\%20Sousa\%20DM.pdf>.

20Tavares CBG, Cáp. 9. In: Carvalho M R, Gomes C F. Amamentação: bases científicas. $4^{\text {a }}$ ed. - Rio de Janeiro: Guanabara Koogan, 2017.

21 Teixeira MM, Vasconcelos VM, Silva DMA, Martins EMCS, Martins MC, Frota MA. Percepções de primíparas sobre orientações no pré-natal acerca do aleitamento materno. Revista da Rede de Enfermagem do Nordeste (Rene). [Internet]. 2013. [acesso em 10 de agosto de 2020]. 14(1): 179-186. Disponivel em: <http://www.periodicos.ufc.br/rene/article/view/3353/259 